\title{
ANN CONTROLLER FOR STATCOM TO ENHANCE PERFORMANCE OF MULTI-MACHINE POWER SYSTEMS INCLUDING SCG
}

\author{
R. A. Amer, G. A. Morsy and H. A. Yassin \\ Electrical Engineering Department, Faculty of Engineering, \\ Minoufiya University, Shebin El-Kom, Egypt
}

\begin{abstract}
Artificial neural network (ANN) control for static compensator (STATCOM) to improve the performance of power systems is presented. The proposed control strategy is applied on a STATCOM attached to a multi-machine power system including a superconducting generator (SCG). The proposed control method, ANN-STATCOM is designed based on proportional integral derivative (PID) by means of minimization of the system deviations. To obtain accurate results, detailed nonlinear models are used for the SCG and the STATCOM. In view of power system control, various types of control systems are employed such as PID controller for SCG in its governor loop and AVRs and PSSs for conventional units in their excitation loops. The performance enhancement provided by the ANN-STATCOM controller is compared with that obtained using a fixed-parameter PID-STATCOM controller. The simulation results demonstrate the effectiveness of the proposed ANN-STATCOM controller in enhancing the power systems performance for various disturbances and at different operating conditions.

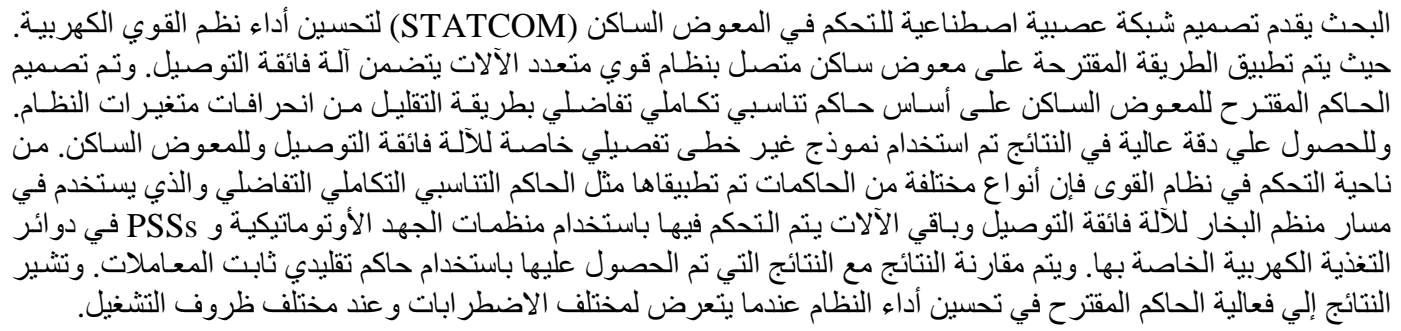

Keywords: Power system control, Superconducting generator, Static compensator, ANN control.

\section{INTRODUCTION}

The rapid development of power electronic switching technology provides opportunities to develop fast power converters to improve the dynamic performance of power systems [1]. During the last decade, Flexible AC transmission systems (FACTS) technologies have been proposed and implemented for power flow control, voltage stabilization and damping oscillation and harmonic filtering damping of power oscillations [2]. Several FACTS-devices have been introduced for various applications such as the thyristor based static var compensator (SVC) which is a widely applied technology; others based voltage source converter (VSC) such as static compensator (STATCOM) is being used in a growing number of installations worldwide [3, 4].

STATCOM is a shunt-connected FACTS device based synchronous generator that generates threephase voltage using VSC from a DC capacitor [5].
The magnitude control of the STATCOM voltage, provides a shunt compensation by exchanging reactive power between the STATCOM and the transmission system. In addition to reactive power exchange, STATCOM can also improve stability and increase damping characteristics of the power systems if a proper damping controller is designed [6]. To maximize the benefits of STATCOM, much effort has been put to investigate the control capability of such devices to improve system stability [7].

Although Superconducting generators (SCGs) have many advantages such as high efficiency, generation at transmission line voltages, reduced size and weight as well as environmental advantages due to reduced oil consumption and $\mathrm{CO}_{2}$ emissions [8], the SCGs require a special attention and more considerations due to the field winding zero resistance and the corresponding extreme long time constant, which 
makes the SCG excitation control is not effective. Hence, the governor control loop is the only permissible control loop for its performance enhancement [9].

Various conventional controllers with fixed parameters have been employed for STATCOM as lead-lag compensator and PID [6]. These conventional controllers are designed at a certain operating condition and due to the load changes or the power system operating conditions daily changes, these controllers which insure good performance under a certain operating condition may be not suitable for other conditions. To maintain better performance under a wide range of operating conditions, self tuning adaptive controllers have been developed [10].

Since 1989, ANNs methodology has captured interest in electrical power engineering and has promised to ensure effective system performance enhancement [11].The use of artificial neural networks (ANNs) offers an attractive alternative for the STATCOM's control. The ANNs are able to model on-line nonlinear, MIMO (multiple inputsmultiple outputs), and non-stationary systems. The ANNs nature makes them robust, adaptive, optimum and hybrid control techniques with attractive features to power system control [12].

This paper presents an alternative control approach using the ANN control strategy for STATCOM to improve the performance of a multi-machine power system including a SCG. The ANN scheme was trained by on-line unsupervised (self learning) ANN based PID controller using an optimization technique to minimize the system deviations in most common operating conditions. The ANN system consists of one input, one hidden and one output layers for each parameter. The simulation results obtained with ANN-STATCOM controller is compared with others obtained using conventional PID-STATCOM controller. These results reveal that the ANN controller is more flexible and robust for the system when subjected to various disturbances in a wide range of operating conditions.

\section{STUDIED POWER SYSTEM}

The considered multi-machine power system is a 10 machine, 39 bus and 19 load area power system [13]. The single line diagram of the studied power system is represented in Fig. 1. The power system is involving a VSC based FACTS-device (STATCOM). All loads are treated as lumped impedances and the transmission system is expressed as nominal $\pi$ double-circuit lines. The generating units are nine conventional units with different types and ratings and one SCG unit. The generating units parameters are listed in Appendix-A. In view of modeling, each conventional generating unit is represented by its reduced third-order model. However, a detailed representation model is used for the SCG with its control systems. This detailed model is important especially for the SCG which has different construction criterions [8].

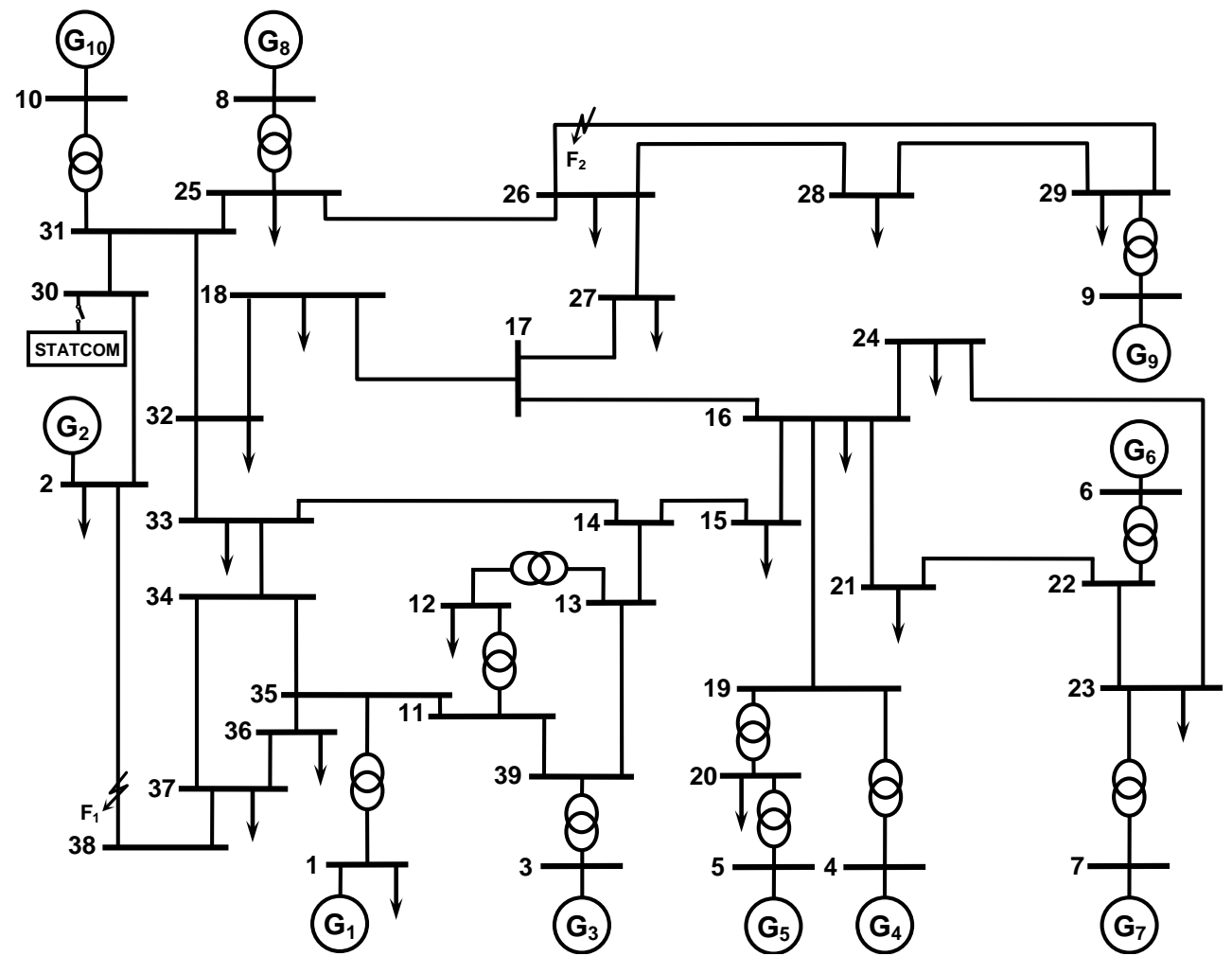

Fig. 1 Single line diagram of the studied electrical power system including a STATCOM 
The rotor screens are the most critical part in the modeling of the SCG. Each screen is represented by two fixed parameters coils, one on each axis [9]. Also, all nonlinearities and constraints of the SCG governor valves movements are taken into consideration. The system generating units are equipped with various types of exciters (slow and fast acting thyristor exciters) and with different ceiling voltages.

\section{SYSTEM MODELLING}

This section describes the mathematical model for each component of the studied power system. These models involve generating units, network solution, excitation systems and the FACTS-device.

\subsection{GENERATING UNITS MODELING}

\subsubsection{SCG Model}

The SCG is represented by a detailed non-linear model. The order of the mathematical model is nine equations for the SCG (to cater the doubly screened rotor) and six for the turbine system that consists of a three stage turbine with reheat and parallel governing system [9]. The SCG is a low inertia unit so, it is equipped with fast valving routine to improve its stability. The SCG mathematical model is described in [9].

\subsubsection{Conventional Generators Models}

Based on park's d-q axes, a third-order nonlinear mathematical model representation is established to represent each conventional machine [13].

To reduce the system order, the mechanical input torques are assumed to be fixed for conventional machines.

\subsection{FACTS-DEVICES MODELING}

Any multi-machine power system including a shunt FACTS-device can be represented as shown in Fig. 2. The study firstly considers these devices as generators which inject current $I_{\mathrm{s}}$ as shown in Fig. 2 . Then, this current is used to determine the individual reference voltage for each generator. The individual reference current is calculated from the generator model and transformed to the common reference current. The common reference current injected by the FACTS-device is calculated from its model. These values are used to calculate the common reference voltage for the FACTS-device and for each generator.

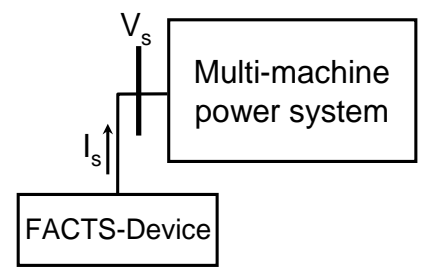

Fig. 2 The representation of the shunt FATS-Device

\subsubsection{STATCOM Model}

The STATCOM is a versatile shunt injection FACTS device based on VSC. This acts as a sinusoidal voltage source of variable phase and magnitude the manipulation of which permits the control of the real and reactive power flow. The STATCOM equivalent circuit is shown in Fig. 3.

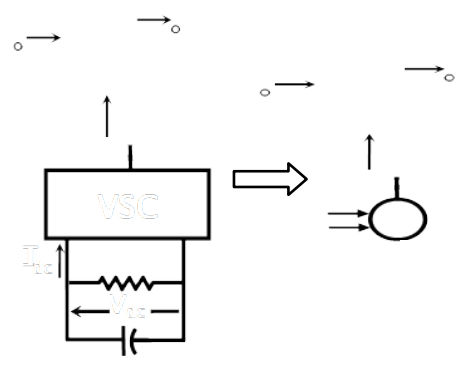

Fig. 3 The STATCOM equivalent circuit

Based on $d-q$ axes rotate with the common reference $D-Q$ axes, the STATCOM nonlinear firstorder differential equations [14]:

$$
\begin{aligned}
& \stackrel{\mathrm{I}}{\mathrm{SD}}=\frac{\omega_{\mathrm{o}}}{\mathrm{X}_{\mathrm{S}}}\left(\mathrm{V}_{\mathrm{ID}}-\mathrm{V}_{\mathrm{SD}}-\mathrm{I}_{\mathrm{SD}} \mathrm{R}_{\mathrm{S}}+\mathrm{I}_{\mathrm{SQ}} \mathrm{X}_{\mathrm{S}}\right) \\
& \mathrm{I}_{\mathrm{SQ}}=\frac{\omega_{\mathrm{o}}}{\mathrm{X}_{\mathrm{S}}}\left(\mathrm{V}_{\mathrm{IQ}}-\mathrm{V}_{\mathrm{SQ}}-\mathrm{I}_{\mathrm{SQ}} \mathrm{R}_{\mathrm{S}}-\mathrm{I}_{\mathrm{SD}} \mathrm{X}_{\mathrm{S}}\right)
\end{aligned}
$$

The DC link capacitor will exchange energy with the system and its voltage will be varied through the first-order differential equation:

$$
\mathrm{V}_{\mathrm{dc}}=-\frac{1}{\mathrm{C}_{\mathrm{s}}}\left(\frac{\mathrm{P}_{\mathrm{ac}}}{\mathrm{V}_{\mathrm{dc}}}+\mathrm{G}_{\mathrm{s}} \mathrm{V}_{\mathrm{dc}}\right)
$$

where,

$\mathrm{P}_{\mathrm{ac}}=\mathrm{V}_{\mathrm{ID}} \mathrm{I}_{\mathrm{SD}}+\mathrm{V}_{\mathrm{IQ}} \mathrm{I}_{\mathrm{SQ}}$

The STATCOM model produces the current injected to its connected bus. This current is used in network calculation using the system admittance matrix. The model of STATCOM is shown in Fig. 4.

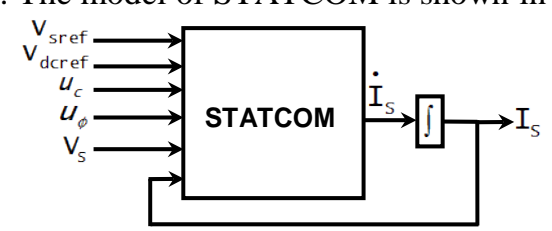

Fig. 4 STATCOM model representation

\section{GENERATING UNITS CONTROL SYSTEMS}

This section illustrates the control systems used for each generating unit in the studied power system.

\subsection{Conventional Generators Control Systems}

In this study, conventional generators are controlled via typical excitation systems using various types of exciters with different ceiling voltages. In this control scheme the generators $G_{1}$ and $\mathrm{G}_{6}$ are equipped with fast acting thyristor exciters 
with negligible time-lag. The other conventional generators are equipped with rotary exciter types. High gains automatic voltage regulators (AVRs) are used with these exciters to control generators terminal voltages. The block diagram representation for conventional generators excitation systems is shown in Fig. 5.

Under heavy load conditions the continuously acting of excitation systems produce a negative damping to the system oscillations. To eliminate this undesired effect and in general to improve the system damping, an artificial network producing torque in the speed phase is introduced. The network used to add a signal that control the synchronous machine terminal voltage is called power system stabilizer (PSS) network [15]. The PSS is a lead-lag network with two time constants $T_{1}$ and $T_{2}$ and gain $G_{s}$. The PSS attached to the excitation system is shown in Fig. 5. The PSS transfer function is given by:

$\frac{y_{s}}{\omega}=G_{s} \frac{1+T_{1} s}{1+T_{2} s}$

where, $\mathrm{y}_{\mathrm{s}}$ is the control signal and $\omega$ is the machine speed deviation. The ratio $\mathrm{T}_{1} / \mathrm{T}_{2}$ is 10 [15].

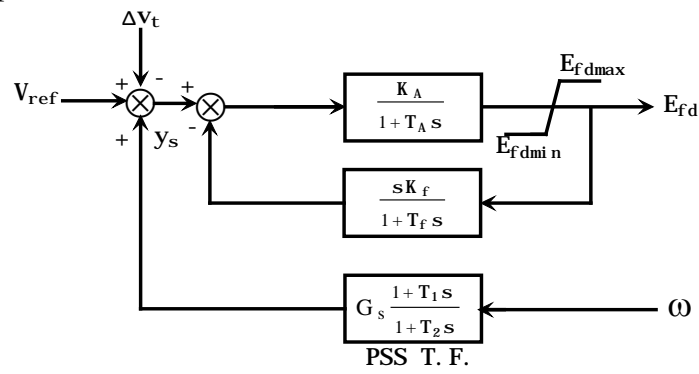

Fig. 5 Excitation system for conventional generating units

\subsection{SCG Control System}

Excitation control is ineffective in improving the performance of the SCG due to the very long time constant of its field winding and the shielding effects of the two rotor screens which are designed to protect the superconducting field winding from armature transients and also prevents any events in the field winding to be effective at the stator winding. Moreover, the magnitude and rate of change of the excitation current and field flux must not exceed certain limits otherwise the superconducting element goes normal (quench) [8]. So, this renders the necessity of considering only the governor control loop to enhance the system performance. Adding positive damping via the governor loop is very difficult and requires a great deal of attention [9].

The SCG is driven by a three stages steam turbine system with reheat and fast acting electro-hydraulic governor. In this study, a PID controller designed according to pole placement technique, is used as a control system for the SCG in its governor control loop as shown in Fig. 6. The PID controller parameter values are obtained as $K_{p}=0.182668$, $\mathrm{K}_{\mathrm{i}}=0.000125366$, and $\mathrm{K}_{\mathrm{d}}=0.072285$ respectively.

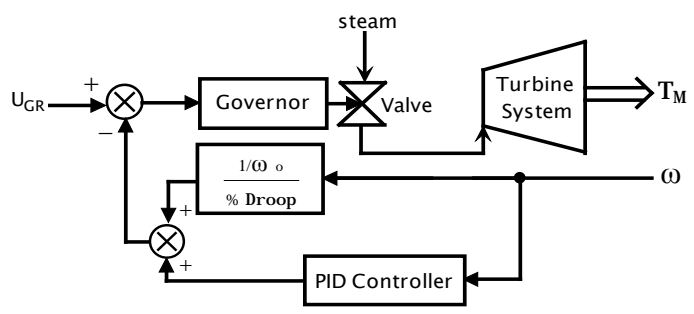

Fig. 6 The SCG governor control system

\section{STATCOM CONTROL SYSTEMS}

The STATCOM may be represented in the same way as a controlled synchronous condenser, which its output voltage magnitude and angle are determined by control systems. The STATCOM is equipped with PID controllers to set its output voltage. The STATCOM control system shown in Fig. 7.

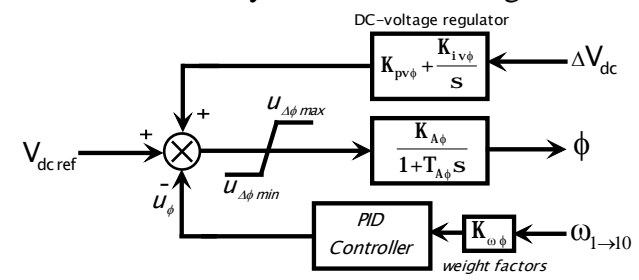

(a) Phase control

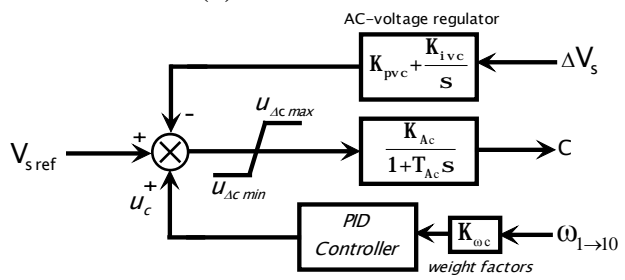

(b) Magnitude control

Fig. 7 The STATCOM control system

\subsection{Conventional PID-STATCOM Controller}

The PID controller is relatively simple in practical implementation and can enhance the system performance particularly to minimize post fault oscillations. Pole placement technique is used in order to determine the controller parameters. The STATCOM regulators and controllers parameters are listed in Appendix A.

The PID controllers transfer functions are given by:

$$
\left.\begin{array}{l}
\mathrm{H}_{\mathrm{c}}(\mathrm{s})=\mathrm{K}_{\mathrm{pc}}+\frac{\mathrm{K}_{\mathrm{ic}}}{\mathrm{S}}+\mathrm{K}_{\mathrm{dc}} \mathrm{S} \\
\mathrm{H}_{\phi}(\mathrm{s})=\mathrm{K}_{\mathrm{p} \phi}+\frac{\mathrm{K}_{\mathrm{i} \phi}}{\mathrm{S}}+\mathrm{K}_{\mathrm{d} \phi} \mathrm{S}
\end{array}\right\}
$$

\subsection{ANN controller design for STATOM}

The conventional PID controller is designed according to a certain operating point and its parameters are fixed. To overcome the drawbacks of 
the conventional controllers, ANN strategies are proposed due to its simple structure, adaptability, robustness and considering the power grid nonlinearities. To obtain the optimal values of ANN based PID controller parameters, two ANNs are established to take the place of $\mathrm{PID}_{\phi}$ and $\mathrm{PID}_{\mathrm{c}}$ damping controllers. The inputs to the ANNs are the deviation in the transmission line active and reactive powers and its output is only one PID parameter. So, the proposed ANN construction is repeated three times for each controller parameter (three for $\mathrm{PID}_{\phi}$ and three for PID $_{\mathrm{c}}$ ).

Fig. 8 shows the construction of one network of these ANNs group, which consists of one input layer, one hidden layer (3-neurons) with a hyperbolic tangent sigmoid activation function and one output with a pureline activation function. The complete ANN controller system $\left(\mathrm{PID}_{\phi}\right)$ is illustrated in Fig. 9. The ANNs weights and biases are adjusted by minimizing the system performance index. The system performance index $(\mathrm{J})$ is taken as the total sum of the system deviations multiplied by the square of the time:

$\mathrm{J}=\int_{0}^{\infty} \mathrm{e}(\mathrm{t}) * \mathrm{t}^{2}$

where, $\mathrm{e}(\mathrm{t})=\Sigma$ All of the system output deviations. Such as speed, rotor angle, valve position, etc.\}.

The minimization of the performance index is implemented by the use of MATLAB optimization toolbox.

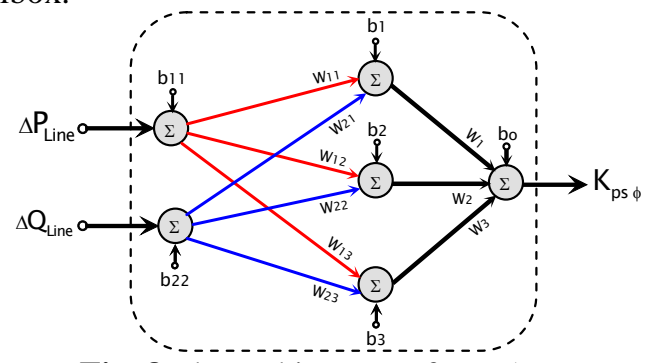

Fig. 8 The architecture of one ANN

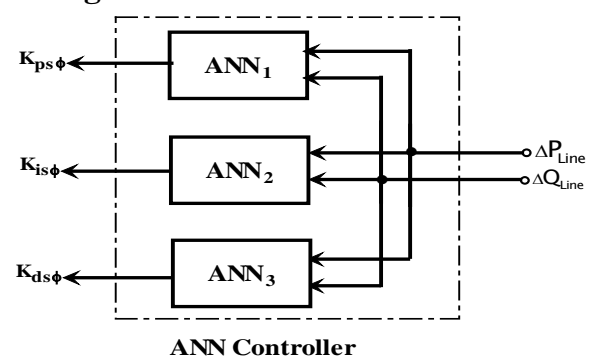

Fig. 9 The ANN controller with all components

\section{Optimal location of STATCOM}

STATCOM is placed at a suitable bus to enhance the power system stability and to improve the damping characteristics of the power system. The system performance index technique is applied to choose the optimal location. The power system transient performance is obtained when it is subjected to a 3-phase short circuit. Fig. 10 shows the values of performance index for different buses location when the STATCOM is equipped with PID controller with feedback signal of the speed deviations for all generators. According to the values of the performance index, the optimal location for the STATCOM is at bus 30 .

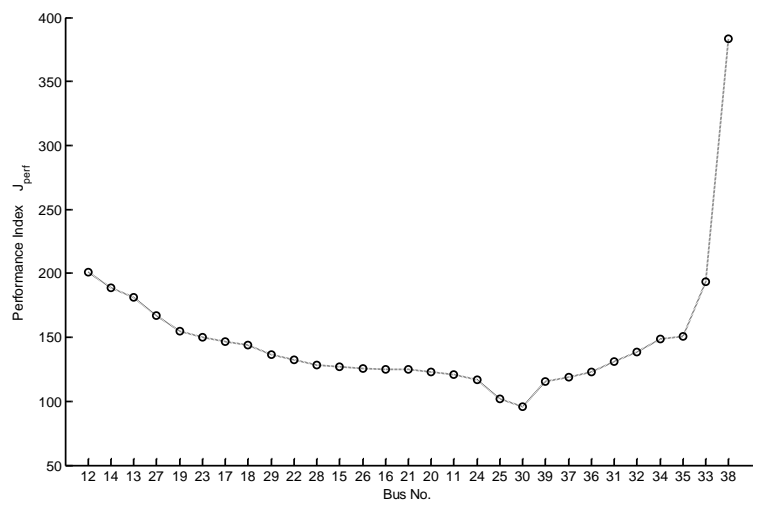

Fig. 10 The system performance index versus the STATCOM location

\section{SIMULATION RESULTS}

The time response of the studied multi-machine power system involving a STATCOM is illustrated when it is subjected to different disturbances. The STATCOM controllers (PID and ANN) parameters are optimally designed when coordinated with the power system controllers by the help of MATLAB optimization techniques. The conventional generators rotor angles and the SCG rotor angle and valve position are used to evaluate the effectiveness of the proposed control schemes. The simulation results are obtained in a comparative form to show the positive effect of the ANN-STATCOM on the system performance.

Fig. 11 shows the response when the system is subjected to a 3-phase short circuit at $F_{1}$. This figure illustrates the significant improvement of the system performance as the STATCOM adds more damping. For Fig. 12, the comparison is focused on the effect of STATCOM-controllers only. The figure shows that, the system response with ANN-STATCOM is more damped and all system variables return to their initial values quickly compared with the PIDSTATCOM. Fig. 13 shows the dynamic response of the system when subjected to a $10 \%$ increase in SCG mechanical input. These results confirm the ability of ANN-STATCOM to enhance the system performance. 

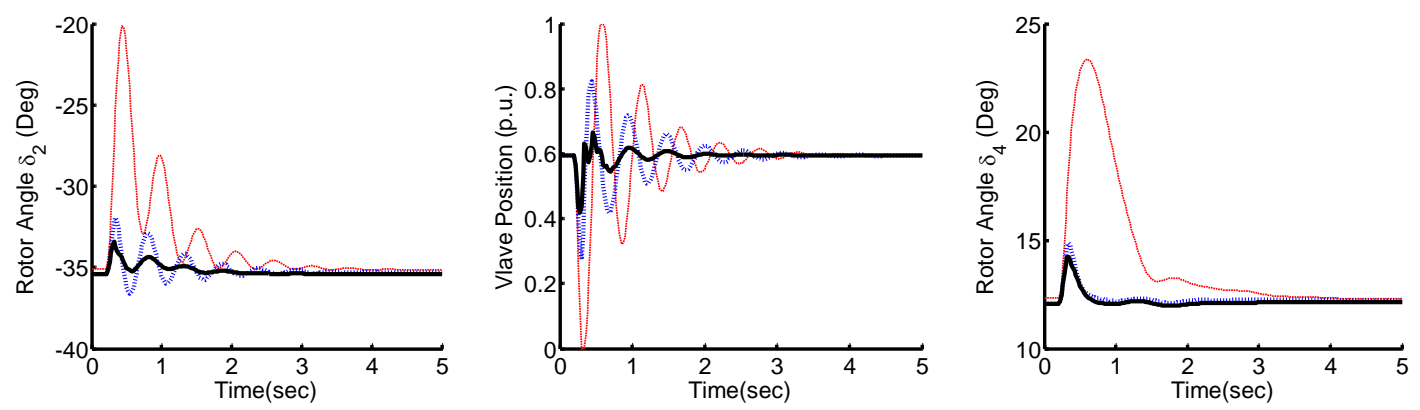

Fig. 11 System transient response to a 3-phase short circuit for a $100 \mathrm{~ms}$ at $\mathrm{F}_{1}$

----- Without STATCOM \& PID on SCG \& AVR + PSS on Conventional Units

...... PID-STATCOM Controller \& PID on SCG \& AVR + PSS on Conventional Units
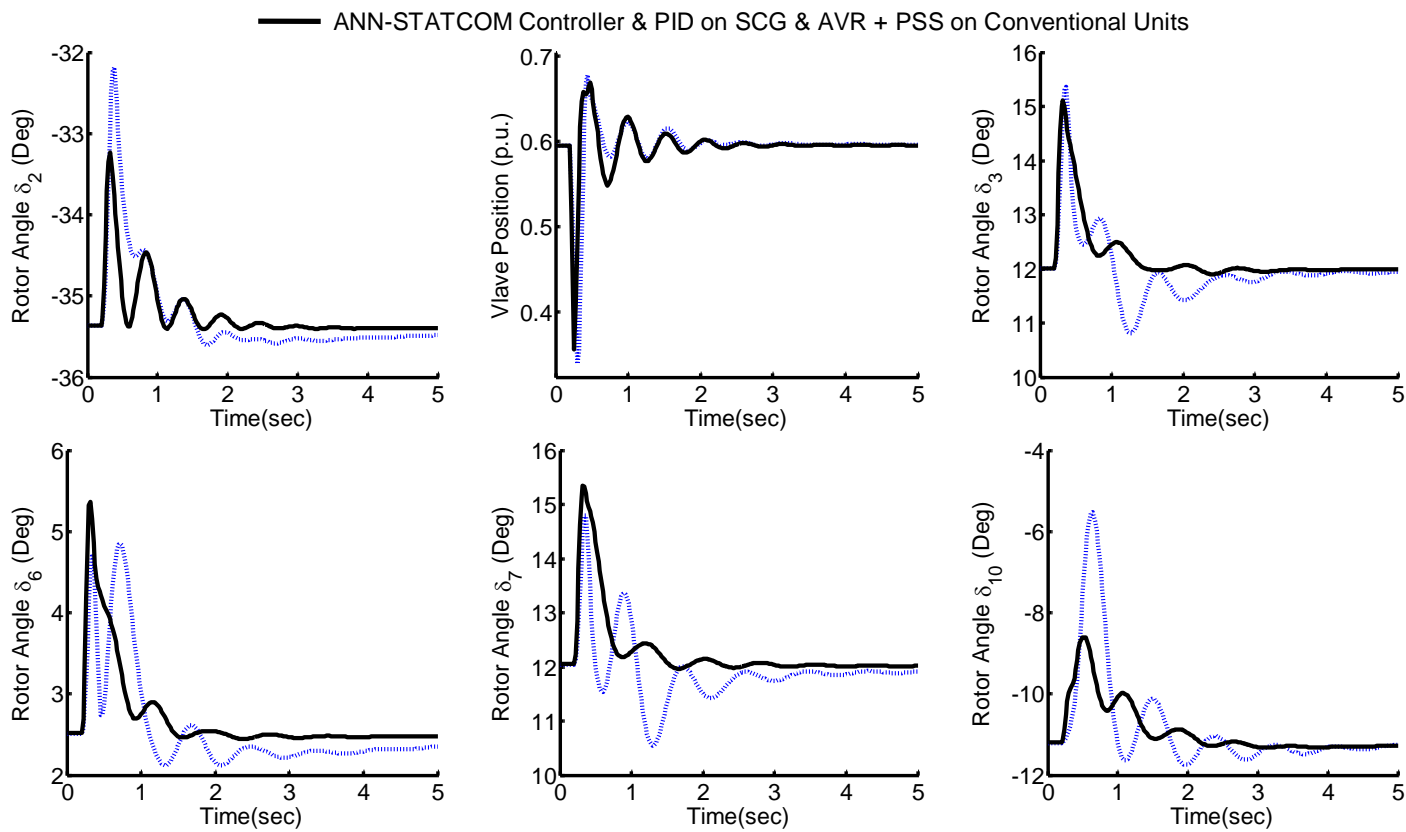

Fig. 12 System transient response to a 3-phase short circuit for a $100 \mathrm{~ms}$ at $\mathrm{F}_{2}$
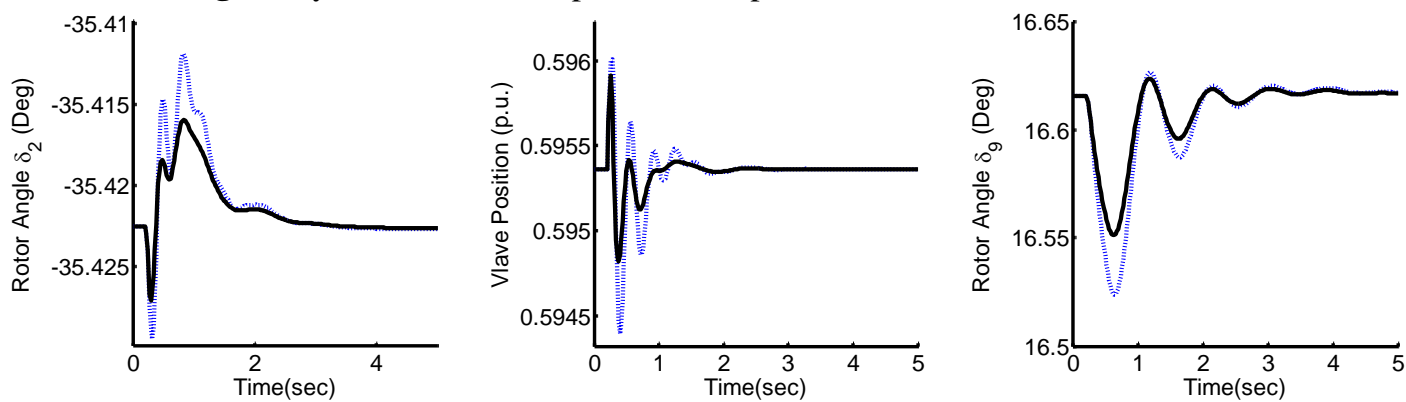

Fig. 13 Dynamic response to a 10\% load increase at bus 16 for $100 \mathrm{~ms}$

...... PID-STATCOM Controller \& PID on SCG \& AVR + PSS on Conventional Units - ANN-STATCOM Controller \& PID on SCG \& AVR + PSS on Conventional Units

\section{CONCLUSIONS}

This paper presents the design of the ANNSTATCOM controllers based PID-STATCOM to enhance the power system performance. The control strategy has been implemented on a STATCOM attached to a multi-machine power system. In this study the SCG is equipped with PID controller in the governor loop and other units are equipped with
AVRs and PSSs in their excitation loops. The STATCOM output voltage is controlled either by conventional PID or by ANN controllers. The conventional PID-STATCOM is designed using the system deviations optimization. The ANNs main task is to adapt the controller parameters to the operating condition. The simulation results show that, the ANN control for STATCOM provides significant damping characteristics over the conventional controller for 
various disturbances at a wide range of operating conditions.

\section{REFERENCES}

[1] E. Acha, et al, "Power Electronic Control in Electrical Systems", NEWNES power engineering series, ISBN 075065126 1, 2002.

[2] M.S. ElMoursi, "Flexible AC Transmission FACTS-Technology and Novel Control Strategies for Power System Stabilization Enhancement”, Ph. D. thesis, University of New Brunswick, May 2005.

[3] V.K. Sood, "HVDC and FACTS Controllers: Applications of Static Converters in Power Systems”, Book published by Kluwer Academic press, e- ISBN: 1-4020-7891-9, 2004.

[4] X.P. Zhang, C. Rehtanz and B. Pal, "Flexible AC Transmission Systems: Modelling and Control”, ISBN-10 3-540-30606-4, SpringerVerlag Berlin Heidelberg, 2006.

[5] A. Jain, et al, "Voltage Regulation With STATCOMs: Modeling, Control and Results, IEEE Transactions on Power Delivery, vol. 21, No. 2, pp. 726-735, April 2006.

[6] K.R. Padiyar, V. S. Prakash, “Tuning and performance evaluation of damping controller for a STATCOM", Electrical Power and Energy Systems, vol. 25, pp.155-166, 2003.

[7] S.F. Faisal, A. H. M. A. Rahim, J. M. Bakhashwain, “A Robust STATCOM Controller for a Multi-Machine Power System Using Particle Swarm Optimization and LoopShaping”, International Journal of Electrical, Computer, and Systems Engineering, Vol. 1 No. 1, ISSN 1307-5179, pp. 64-70, 2007.

[8] H.A. Khattab, "Stabilization of A Superconducting Generating Unit In A Multimachine System”, Ph.D. Thesis, Menoufia University, Faculty of Eng. 2007.

[9] G.A. Morsy, H.A. Kattab and A. Kinawy, "Design of a PI controller for a superconducting generator”, Eng. Research. Vol. 23, No. 1, Fac. of Eng., Men., Univ., pp. 61-77, January 2000.

[10]G.P. Chen, O.P. Malik, et al, "An Adaptive power system stabilizer based on the selfoptimizing pole shifting control strategy", submitted to IEEE/PES winter meeting 1993.

[11] M. JUAN, et al, "Neural Network Control of the STATCOM in Multimachine Power Systems", WSEAS Transactions on Power Systems, No. 9, Vol. 2, pp. 209-214, ISSN 1790-5060, 2007.

[12] G.K. Venayagamoorthy, et al, "Implementation of adaptive critic-based neurocontrollers for turbogenerators in a multimachine power system”, IEEE Trans. Neural Networks, vol. 14, No. 5, pp. 1047-1064, 2003.
[13] A.S. Bazanellaa, A.S. e Silvab, "Coordinated design of damping controllers for robustness of power systems stability”, Electrical Power and Energy Systems, Vol. 23, pp 69-79, 2001.

[14] N.C. Sahooa et al, "Application of a multivariable feedback linearization scheme for STATCOM control”, Electric Power Systems Research, Vol. 62, Issue 2, pp 81-91, 2002.

[15]A.H .El-abiad, "Power systems analysis and planning”, Purdue University, West Lafayette, Indiana USA, 1983.

\section{APPENDICES}

\section{Appendix A}

\section{Superconducting Generator Parameters:}

2000 MVA, 1700 MW, 3000 rpm

$\mathrm{X}_{\mathrm{d}}=\mathrm{X}_{\mathrm{q}}=0.5457$ p.u., $\mathrm{X}_{\mathrm{D} 1}=\mathrm{X}_{\mathrm{Q} 1}=0.2567$ p.u.

$\mathrm{X}_{\mathrm{D} 2}=\mathrm{X}_{\mathrm{Q} 2}=0.4225$ p.u., $\mathrm{X}_{\mathrm{f}}=0.541$ p.u., $\mathrm{R}_{\mathrm{a}}=0.003$ p.u.

$\mathrm{X}_{\mathrm{fd}}=\mathrm{X}_{\mathrm{fD} 1}=\mathrm{X}_{\mathrm{dD} 1}=\mathrm{X}_{\mathrm{dD} 2}=\mathrm{X}_{\mathrm{D} 1 \mathrm{D} 2}=0.237$ p.u.

$\mathrm{X}_{\mathrm{qQ} 1}=\mathrm{X}_{\mathrm{qQ} 2}=\mathrm{X}_{\mathrm{Q} 1 \mathrm{Q} 2}=0.237$ p.u., $\mathrm{X}_{\mathrm{fD} 2}=0.3898$ p.u.

$\mathrm{R}_{\mathrm{D} 1}=\mathrm{R}_{\mathrm{Q} 1}=0.1008$ p.u., $\mathrm{R}_{\mathrm{D} 2}=\mathrm{R}_{\mathrm{Q} 2}=0.00134$ p.u.

Field time constant $=750$ sec., $\mathrm{H}=3 \mathrm{KW} . \mathrm{s} / \mathrm{KVA}$.

Table 1 Conventional machines parameters

\begin{tabular}{|c|c|c|c|c|c|c|}
\hline Unit & $\mathbf{G}_{\mathbf{1}}$ & $\mathbf{G}_{\mathbf{3}, \mathbf{4}, \mathbf{7}}$ & $\mathbf{G}_{\mathbf{5 , ~}}$ & $\mathbf{G}_{\mathbf{6}}$ & $\mathbf{G}_{\mathbf{9}}$ & $\mathbf{G}_{\mathbf{1 0}}$ \\
\hline $\mathbf{M V A}_{\text {Rated }}$ & 920.35 & 835 & 615 & 896 & 1070 & 410 \\
$\mathbf{X}_{\mathbf{d}}$ (p.u.) & 1.7900 & 2.1830 & 0.8979 & 1.7900 & 1.933 & 1.7668 \\
$\mathbf{X}_{\mathbf{d}}^{\prime}$ (p.u.) & 0.3550 & 0.4130 & 0.2995 & 0.2200 & 0.4670 & 0.2738 \\
$\mathbf{X}_{\mathbf{q}}$ (p.u.) & 1.6600 & 2.1570 & 0.6460 & 1.7150 & 1.7430 & 1.7469 \\
$\mathbf{X}_{\mathbf{q}}^{\prime}$ (p.u.) & 0.5700 & 1.2850 & 0.6460 & 0.4000 & 1.1440 & 1.0104 \\
$\mathbf{T}_{\mathbf{d o}}^{\prime}$ (s) & 7.9000 & 5.6900 & 7.4000 & 4.3000 & 6.6600 & 5.4320 \\
$\mathbf{H}_{\text {(s) }}^{(\mathbf{s})}$ & 3.7638 & 2.6424 & 5.148 & 2.9297 & 3.0953 & 3.7041 \\
$\mathbf{K}_{\mathbf{d}}$ & 2.00 & 2.00 & 2.00 & 2.00 & 2.00 & 2.00 \\
\hline
\end{tabular}

Table 2 Excitation systems and PSSs parameters

\begin{tabular}{|c|c|c|c|c|c|c|}
\hline Unit & $\mathbf{G}_{\mathbf{1}}$ & $\mathbf{G}_{\mathbf{3 , 4}, \mathbf{7}}$ & $\mathbf{G}_{\mathbf{5 , ~}}$ & $\mathbf{G}_{\mathbf{6}}$ & $\mathbf{G}_{\mathbf{9}}$ & $\mathbf{G}_{\mathbf{1 0}}$ \\
\hline $\mathbf{K}_{\mathbf{A}}$ (p.u.) & 25.000 & 400 & 200 & 250 & 400 & 400 \\
$\mathbf{T}_{\mathbf{A}}$ (s) & 0.20 & 0.02 & 0.02 & 0.20 & 0.02 & 0.02 \\
$\mathbf{K}_{\mathbf{F}}$ (p.u.) & 0.084 & 0.030 & 0.010 & 0.036 & 0.060 & 0.030 \\
$\mathbf{T}_{\mathbf{F}}$ (s) & 1.00 & 1.00 & 1.00 & 1.00 & 1.00 & 1.00 \\
$\mathbf{E}_{\text {fdmax }}$ (p.u.) & 4.31 & 5.02 & 7.32 & 5.15 & 4.80 & 3.29 \\
$\mathbf{E}_{\text {fdmin }}$ (p.u.) & -4.31 & 0.00 & 0.00 & -5.15 & 0.00 & 0.00 \\
$\mathbf{G}_{\text {S }}$ (p.u.) & 0.03 & 0.03 & 0.03 & 0.03 & 0.03 & 0.03 \\
$\mathbf{T}_{\mathbf{1}}$ (s) & 0.15 & 0.15 & 0.15 & 0.15 & 0.15 & 0.15 \\
$\mathbf{T}_{\mathbf{2}}$ (s) & 0.015 & 0.015 & 0.015 & 0.015 & 0.015 & 0.015 \\
\hline
\end{tabular}

\section{STATCOM Parameters:}

$\mathrm{G}_{\mathrm{s}}=1 / 28$ p.u., $\mathrm{C}_{\mathrm{s}}=1$ p.u., $\mathrm{K}_{\mathrm{s}}=0.9$ p.u.

$\mathrm{K}_{\mathrm{pc}}=0.19024, \mathrm{~K}_{\mathrm{ic}}=0.39253, \mathrm{~K}_{\mathrm{dc}}=0.00207$

$\mathrm{K}_{\mathrm{p} \phi}=0.44093, \mathrm{~K}_{\mathrm{i} \phi}=0.71248, \mathrm{~K}_{\mathrm{d} \phi}=0.0063$

$\mathrm{K}_{\mathrm{pv} \phi}=0.71002, \mathrm{~K}_{\mathrm{iv} \phi}=0.33503$

$\mathrm{K}_{\mathrm{pvc}}=0.39921, \mathrm{~K}_{\mathrm{ivc}}=0.62223$. 